\title{
The clinical course of COVID-19 in systemic sclerosis patients, report from 150 patients
}

\author{
Zahra Tamartash $^{1} \cdot$ Ali Javinani $^{1} \cdot$ Farhad Gharibdoost $^{1} \cdot$ Reza Atef Yekta $^{2} \cdot$ Amirmohammad Mohammadzadegan $^{1}$. \\ Hoda Kavosi ${ }^{1}$ (i)
}

Received: 22 December 2020 / Accepted: 27 March 2021 / Published online: 16 April 2021

(c) Società Italiana di Medicina Interna (SIMI) 2021

\section{Dear Editor,}

The recent pandemic of Severe Acute Respiratory Syndrome Coronavirus 2 (SARS-CoV-2) has led to worldwide uncertainty about the potential risks to those with autoimmune diseases [1]. Long-term immunosuppression in patients with rheumatic diseases is a major concern. As already known, microbial infections have a more severe and complicated course in immunocompromised patients [2]. However, the clinical course of Coronavirus Disease 2019 (COVID-19) in this high-risk population is still unknown [1].

Systemic Sclerosis ( $\mathrm{SSc}$ ) is a systemic autoimmune disease with multi-organ manifestations secondary to fibrosis and vasculopathy. Cardiopulmonary involvement is a major problem and the main cause of mortality in these patients [3]. Theoretically, the synergistic effect of long-term immunosuppression and underlying pulmonary involvement renders these patients susceptible to a more severe form of COVID-19 [1].

In this letter, we reported clinical data on COVID-19 in 150 patients with SSc. To the best of our knowledge, this is the first report focusing exclusively on the clinical features of COVID-19 in SSc patients. We studied 150 patients with SSc from February 20 to August 20, 2020, and all patients were on treatment with immunosuppressants. During in-person or virtual visits, the patients were asked to complete a questionnaire about their clinical manifestations of COVID19 and their medications. All patients gave informed consent to have their data used for research purposes.

Hoda Kavosi

h-kavosi@sina.tums.ac.ir

1 Rheumatology Research Center, Tehran University of Medical Science (TUMS), 1411713137, Tehran, Iran

2 Anesthesiology Department, Shariati Hospital, Tehran University of Medical Sciences, Tehran, Iran
Of 150 patients with SSc (95.3\% female, the mean age of $44.4 \pm 14.5$ years), 14 had symptoms consistent with COVID-19. Seven of 14 (50\%) had a positive Polymerase Chain Reaction (PCR) test for SARS-CoV-2 by rhinopharyngeal sampling, two (14.2\%) had findings suggestive of COVID-19 in their chest Computed Tomography (CT) scans, and five (35.7\%) had the characteristic clinical manifestations of the disease. The immunosuppressive regimen of these 14 patients included prednisolone in $85.7 \%$ of the patients, mycophenolate mofetil in $57.1 \%$, azathioprine in $21.4 \%$, and rituximab in $7.1 \%$ (clinical, laboratory, and imaging findings are listed in Table 1).

In addition, 11 patients (78.5\%) had mild symptoms and were treated as outpatients, while $3(21.4 \%)$ were hospitalized in non-ICU wards due to hypoxemia. There was no mortality. The medical treatment for COVID-19 included hydroxychloroquine for 7 patients (50\%), azithromycin for 5 patients (35.7\%), and Interferon-alpha 1 beta and colchicine for 2 patients.

According to our findings, $6 \%$ of the patients had a positive PCR test for SARS-CoV-2. A previous study in northern Italy reported 65 (4.26\%) PCR-positive cases of COVID-19 in 1525 rheumatologic patients [4]. Moreover, the incidence of COVID-19 was $15 \%$ in a Chinese population of rheumatologic patients treated with biologic agents, all of whom had mild symptoms [5]. In a cohort of SSc patients in Italy, there were only 2 confirmed COVID-19 cases (out of 526), which is compatible with other studies. The lower incidence of COVID-19 in these studies may be due to the strict national obligations and extensive serological testing in the national surveys [6].

Of 14 patients with suspected or confirmed COVID-19, eight $(57.1 \%)$ were suffering from SSc-related interstitial lung disease. However, only three (21.4\%) developed hypoxemia leading to hospitalization, while the other patients had mild disease without respiratory complications and were treated as outpatients. Compatible with our findings, studies 
Table 1 Clinical characteristics of the patients with confirmed or suspected COVID-19

\begin{tabular}{|c|c|c|}
\hline & $\begin{array}{l}\text { Confirmed COVID-19 } \\
\text { Number }=9\end{array}$ & $\begin{array}{l}\text { Highly sugges- } \\
\text { tive of COVID- } \\
19 \\
\text { Number }=5\end{array}$ \\
\hline Number of patients & $9(64.2 \%)$ & $5(35.7 \%)$ \\
\hline Age (yeas) $($ mean $\pm S D)$ & $44.5 \pm 16.6$ & $51.6 \pm 16.1$ \\
\hline Female, $n(\%)$ & $9(100 \%)$ & $5(100 \%)$ \\
\hline \multicolumn{3}{|l|}{ Symptoms } \\
\hline Fever & $3(33.3 \%)$ & $1(20 \%)$ \\
\hline Myalgia & $7(77.7 \%)$ & $5(100 \%)$ \\
\hline Sore throat & $1(11.1 \%)$ & $4(80 \%)$ \\
\hline Cough & $3(33.3 \%)$ & $4(80 \%)$ \\
\hline New dyspnea & $3(33.3 \%)$ & $1(20 \%)$ \\
\hline Decreased $\mathrm{O}_{2}$ saturation & $3(33.3 \%)$ & 0 \\
\hline Amnesia & $5(55.5 \%)$ & $4(80 \%)$ \\
\hline Gastro intestinal problems & $3(33.3 \%)$ & $1(20 \%)$ \\
\hline \multicolumn{3}{|l|}{ SSC treatment } \\
\hline Mycophenolate Mofetil & $4(44.4 \%)$ & $2(40 \%)$ \\
\hline Prednisolone & $8(88.8 \%)$ & $4(80 \%)$ \\
\hline Azathioprine & $1(11.1 \%)$ & $1(20 \%)$ \\
\hline Rituximab & $1(11.1 \%)$ & 0 \\
\hline Angiotensin II receptor blockers & 0 & $1(20 \%)$ \\
\hline Aspirin & $3(33.3 \%)$ & $2(40 \%)$ \\
\hline Proton pomp inhibitor & $3(33.3 \%)$ & $3(60 \%)$ \\
\hline Statin & 0 & $1(20 \%)$ \\
\hline Anticoagulant & $1(11.1 \%)$ & 0 \\
\hline \multicolumn{3}{|l|}{ Disease activity } \\
\hline Active SSC & $4(44.4 \%)$ & $1(20 \%)$ \\
\hline Inactive SSC & $5(55.5 \%)$ & $4(80 \%)$ \\
\hline \multicolumn{3}{|l|}{ Disease status } \\
\hline Known contact with COVID-19 & $1(1.1 \%)$ & 0 \\
\hline Chest CT scan performed & $8(88.8 \%)$ & $1(20 \%)$ \\
\hline Chest CT scan pathological findings & $2(22.2 \%)$ & 0 \\
\hline Rhino pharyngeal swabs PCR test & $7(77.7 \%)$ & 0 \\
\hline Positive Anti-COVID IgG Ab & $1(11.1 \%)$ & 0 \\
\hline Negative Anti-COVID IgG Ab* & $2(22.2 \%)$ & 0 \\
\hline Hospital admission & $3(33.3 \%)$ & 0 \\
\hline Death & 0 & 0 \\
\hline
\end{tabular}

COVID-19 Coronavirus Disease 2019, SD Standard Deviation, SSC Systemic sclerosis, PCR Polymerase chain reaction, IgG $A b$ Immunoglobulin G Antibody

*Other patients did not check Anti-COVID IgG Ab on COVID-19 patients in China reported that $81 \%$ of cases had mild disease and no patient with rheumatologic disease experienced a fatal clinical course [7]. In the mentioned cohort in Italy, which included 526 patients with limited or diffuse SSc with almost equal numbers (270 and 256, respectively), $45 \%$ had interstitial lung disease. Of these patients, only 2 suffered COVID-19 induced pneumonia and one of them had died [6].

We hypothesized that the relatively low prevalence of COVID-19 in our study population was related to the strict health instructions given to our patients. Since the first days of the COVID-19 pandemic in Iran, SSc patients with access to the Internet and social media were instructed to wear face masks, strictly adhere to hand hygiene protocols, and avoid unnecessary personal communication. Patients with a medical emergency were visited by a rheumatologist via telemedicine.

In conclusion, SSc patients have a COVID-19 similar clinical presentation to the normal population. However, further studies are needed to elucidate the puzzling effects 
of SARS-CoV-2 on patients with underlying autoimmune diseases.

\section{Declarations}

Conflict of interest The authors declare that there is not any conflict of interest.

Ethical approval All procedures performed in studies involving human participants were in accordance with the ethical standards of the institutional and/or national research committee and with the 1964 Helsinki declaration and its later amendments or comparable ethical standards.

Informed consent In addition, informed consent was obtained from all individual participants included in the study.

\section{References}

1. Ferro F, Elefante E, Puxeddu I, Baldini C, Bartoloni E, Baratè C et al (2020) COVID-19: the new challenge for rheumatologists. First update. Clin Exp Rheumatol 38(3):373-382

2. Monti S, Balduzzi S, Delvino P, Bellis E, Quadrelli VS, Montecucco C (2020) Clinical course of COVID-19 in a series of patients with chronic arthritis treated with immunosuppressive targeted therapies. Ann Rheum Dis 79(5):667-668

3. Allanore Y, Gharibdoost F, Jamshidi AR, Javinani A, Avouac J, Rastkar E et al (2019) Comparison of the clinical phenotype of systemic sclerosis patients in Iran and France in two university centers. J Scleroderma Relat Disord 4(2):149-159

4. Fredi M, Cavazzana I, Moschetti L, Andreoli L, Franceschini F, Airò $\mathrm{P}$ et al (2020) COVID-19 in patients with rheumatic diseases in northern Italy: a single-centre observational and case-control study. Lancet Rheumatol 2(9):e549-e556

5. Guan W-j, Ni Z-y, Hu Y, Liang W-h, Ou C-q, He J-x et al (2020) Clinical characteristics of coronavirus disease 2019 in China. $\mathrm{N}$ Engl J Med 382(18):1708-1720

6. Del Papa N, Sambataro G, Minniti A, Maglione W, Pignataro F, Caminati A et al (2020) Impact of COVID-19 outbreak in an Italian cohort of patients with systemic sclerosis. Ther Adv Musculoskelet Dis 12:1759720X20953356

7. Figueroa-Parra G, Aguirre-Garcia GM, Gamboa-Alonso CM, Camacho-Ortiz A, Galarza-Delgado DA (2020) Are my patients with rheumatic diseases at higher risk of COVID-19? Ann Rheum Dis 79(6):839-840

Publisher's Note Springer Nature remains neutral with regard to jurisdictional claims in published maps and institutional affiliations. 